\author{
Marquette University \\ e-Publications@Marquette
}

\title{
Effect of specimen thicknesses on water absorption and flexural strength of CFRP laminates subjected to water or alkaline solution immersion
}

\author{
Xue Zhang \\ Dalian University of Technology \\ Yanlei Wang \\ Dalian University of Technology \\ Baolin Wan \\ Marquette University, baolin.wan@marquette.edu \\ Gaochuang Cai \\ University of Luxembourg \\ Yuan Qu \\ Dalian University of Technology
}

Follow this and additional works at: https://epublications.marquette.edu/civengin_fac

Part of the Civil Engineering Commons

\section{Recommended Citation}

Zhang, Xue; Wang, Yanlei; Wan, Baolin; Cai, Gaochuang; and Qu, Yuan, "Effect of specimen thicknesses on water absorption and flexural strength of CFRP laminates subjected to water or alkaline solution immersion" (2019). Civil and Environmental Engineering Faculty Research and Publications. 240.

https://epublications.marquette.edu/civengin_fac/240 
Marquette University

e-Publications@Marquette

\section{Civil, Construction and Environmental Engineering Faculty Research and Publications/College of Engineering}

This paper is NOT THE PUBLISHED VERSION; but the author's final, peer-reviewed manuscript. The published version may be accessed by following the link in the citation below.

Construction and Building Materials, Vol. 208 (May 30, 2019): 314-325. DOI. This article is (C) Elsevier and permission has been granted for this version to appear in e-Publications@Marquette. Elsevier does not grant permission for this article to be further copied/distributed or hosted elsewhere without the express permission from Elsevier.

\section{Effect of specimen thicknesses on water absorption and flexural strength of CFRP laminates subjected to water or alkaline solution immersion}

Xue Zhang

State Key Laboratory of Coastal and Offshore Engineering, School of Civil Engineering, Dalian University of Technology, Dalian 116024, PR China

Yanlei Wang

State Key Laboratory of Coastal and Offshore Engineering, School of Civil Engineering, Dalian University of Technology, Dalian 116024, PR China

Baolin Wan

Department of Civil, Construction and Environmental Engineering, Marquette University, Milwaukee, WI

Gaochuang Cai

Laboratory of Solid Structures, University of Luxembourg, Luxembourg L1359, Luxembourg 


\title{
Yuan Qu
}

\section{State Key Laboratory of Coastal and Offshore Engineering, School of Civil Engineering, Dalian University of Technology, Dalian 116024, PR China}

\begin{abstract}
In this paper, an experimental research was undertaken to investigate the effect of specimen thicknesses on water absorptions and flexural strengths of wet lay-up CFRP laminates subjected to distilled water or alkaline solution immersion up to 180 days. Test results showed that the water uptake and flexural strength retention of CFRP laminates were significantly affected by the adopted specimen thickness. For the same aging time, the water uptake of CFRP laminates decreased in the early stage of immersion and increased in the later stage of immersion with the increase of specimen thickness. Meanwhile, the flexural strength retention generally increased as specimen thickness increased. In addition, a new thickness-based accelerated method for hygrothermal aging test of CFRP laminates was proposed. The accelerated factors of the water uptake and flexural strength retention of CFRP laminates were theoretically deduced. The proposed analytical model of accelerated factors was verified with current test data, and then applied to predict long-term properties of CFRP laminates. Compared with the traditional temperature-based accelerated method, the new thickness-based accelerated method is much easier to apply to predict long-term properties of CFRP laminates with good accuracy.
\end{abstract}

\section{Keywords}

Carbon Fiber Reinforced Polymer (CFRP), Specimen thickness, Durability, Accelerated method, Water uptake, Flexural strength

\section{Introduction}

Carbon Fiber Reinforced Polymer (CFRP) is increasingly used in civil infrastructures as reinforcing rods, externally bonding or wrapping for strengthening, and even all-composite structural systems [1], [2], [3], [4], [5], [6], [7], [8]. CFRP is generally exposed to aggressive environment during the long service life of these infrastructures [9], [10], [11], [12]. Therefore, the long-term environmental effects (e.g., moisture, temperature, $\mathrm{pH}$, etc.) on the mechanical properties of CFRP (e.g., tensile strength, stiffness, interfacial properties, etc.) have been greatly concerned in recent decades [13], [14], [15], [16], [17].

The durability of CFRPs is influenced by several factors, such as the fiber volume fraction, the manufacturing process, and environmental exposure conditions [18]. Among these factors, the water absorption is one of the main reasons for the degradation of mechanical properties of CFRP composites after long-term duration in service [19]. Therefore, a large number of studies have been undertaken to evaluate the water uptake of CFRP composites and its influence on the mechanical properties of CFRP by aging tests. Karbhari and Xian [20] found that the moisture uptake response of CFRP could be characterized by a two-stage model, which indicated an initial diffusion-based response followed by a relaxation-based one. They also suggested that the long-term properties of pultruded CFRP composites were mainly affected by moisture uptakes through plasticization, swelling, and hydrolysis of the resin matrix. Kafodya et al. [21] investigated water uptakes of pultruded unidirectional CFRP plates immersed in water and seawater with a duration of 20 weeks, and found that the type of solution had little effect on the degradation of CFRPs. Almeida et al. [22] studied the effect of hygrothermal conditioning on mechanical properties of carbon fiber/epoxy filament-wound composite laminates. With the increase of aging time, the trend of water uptake was well fitted with the Fickian model, and the shear strength and modulus of specimens reduced to about $30 \%$ and $38 \%$, respectively. Based on aging 
tests, polyurethane-based pultruded carbon fiber plates (CFRPUs) were conditioned in water, seawater and alkali solution to evaluate their water uptakes and the degradation of mechanical properties [23], [24], [25]. It was found that CFRPUs showed a better moisture resistance than epoxy-based CFRPs. After 1-year duration with all the solutions, tensile properties of CFRPUs kept basically constant while epoxy-based CFRP plates showed noticeable decrease in the tensile strength.

Besides the aforementioned pultruded products, the wet lay-up CFRP laminates are also commonly used in civil engineering projects. Due to the imperfection in hand application, the durability of wet lay-up CFRP laminates is different from that of pultruded products. Zhang et al. [26]evaluated the effect of moisture uptake on bending strengths of wet lay-up CFRP laminates immersed in water for 7 and 14 days. Experimental results revealed that the moisture uptake resulted in a significant degradation of bending strength of CFRPs. To further investigate the degradation mechanism of wet lay-up CFRP laminates due to water immersion, Takeda et al. [27] adopted fiber Bragg grating sensors to monitor water absorptions. Based on the monitoring technique, the swelling strain and coefficient of moisture expansion of unidirectional CFRP laminates were estimated. Saadatmanesh et al. [28] investigated the residual strength of unidirectional CFRP laminates subjected to alkaline and acidic solutions. Test results showed that the tensile mechanical properties of the wet lay-up CFRP laminates were scarcely affected by the humid environments after a duration of 27 months. Through aging tests, Sciolti et al. [29] found that the tensile strength of wet lay-up CFRP laminates decreased by $30 \%$ after immersed in distilled water for 30 weeks.

Based on the aforementioned studies, the trend of water absorption and the degradation of mechanical properties of CFRP composites can be investigated by immersing specimens in different solutions. However, it is still insufficient to use the current findings to quantificationally evaluate the long-term properties of CFRP composites subjected to hygrothermal environments for two reasons.

First, the test temperatures, immersion durations and test methods were deliberately designed to keep consistent in most studies. However, the adopted specimen thicknesses were generally different from each other [20], [21], [22], [23], [24], [25], [26], [27], [28], [29]. This indicates that experimental results based on specimens with different thicknesses are non-comparable and thus cannot be directly used to establish a unified prediction model. It is mainly because that the time needed to reach the fully permeation of CFRP composite is greatly related to the thickness of the specimen when the diffusion rate of immersion solution maintains constant. A similar concern had already been made to the durability of glass fiber reinforced polymer (GFRP) bars with different diameters [30]. It was found that the degradation of mechanical properties of the GFRP bars was significantly influenced by specimens' diameters. However, to the authors' knowledge, such effect has not been considered in the existing durability studies on FRP laminates with different thicknesses, which hampers the development of comparative analysis [31], [32], [33].

Second, the immersion time of the above mentioned aging tests are greatly short compared to the real/designed service life of CFRP composites, thus it is unreasonable to evaluate their long-term durability using such short-term experimental results [34]. To solve this problem, a temperature-based accelerated method (TAM) was proposed to better evaluate the long-term durability of FRP composites [35], [36], [37]. Using this method, FRP composites are usually tested at a high temperature to accelerate the degradation process subjected to aggressive environments, and then the test results based on a relative short aging time can be transformed to evaluate the long-term properties of FRP materials. It was found that, however, the structure of the resin could change from a glassy state to a viscoelastic state when the glass transition temperature $T_{g}$ is reached. Therefore, the use of too high temperature close to $T_{g}$ could not only accelerate the degradation ratebut also modify the thermomechanical-induced degradation mechanisms themselves, leading to an underestimation of the durability of FRP materials [38]. For this reason, TAM is generally recommended to be used under a restricted temperature, which limits its application in practice because of the unstable and low 
accelerated efficiency. Therefore, it is necessary to develop a more effective accelerated testing method to better evaluate the durability of FRP composites. It should be noted that the aging time of FRP laminates needed to achieve a given degradation level is dependent on the thickness of specimens. If the effect of specimen thickness on properties of FRP laminates exposed to aggressive environments is clearly explored, it is possible to establish a new accelerated testing method based on the specimen thickness.

The main targets of this paper are to (1) evaluate the effect of specimen thickness on the water absorption and flexural strength of CFRP laminates immersed in distilled water and alkaline solution, and (2) propose a new thickness-based accelerated method to better predict the water absorption and flexural strength of CFRP laminates. An experimental program was conducted to investigate the water absorption and flexural strength of wet lay-up CFRP laminates with different thicknesses. The effect of specimen thickness on the water absorption and flexural strength retention of CFRP laminates was evaluated based on test results, which suggested that a thickness-based accelerated method could be developed to accelerate the hygrothermal aging test of CFRP laminates. The accelerated factors of water absorption and flexure strength retention of CFRP laminates were respectively deduced and verified with test results of the current study.

\section{Experimental program}

\subsection{Materials and specimen preparation}

The unidirectional carbon fiber sheet (UT70-30 produced by Toray Co., Ltd.) was used in this study. The weight and nominal thickness of the carbon fiber sheet are $300 \mathrm{~g} / \mathrm{m}^{2}$ and $0.167 \mathrm{~mm}$, respectively. According to the manufacturer, the tensile strength, tensile modulus and elongation at break of the carbon fiber sheet are $4077 \mathrm{MPa}, 245 \mathrm{GPa}$, and 1.51\%, respectively. The resin (JGN-T produced by Kaihua Co., Ltd.) adopted in current study was a two-component epoxy with main and curing agentsmixed in the ratio of 3:1 by weight. The mixing density of the resin is $1.1 \mathrm{~g} / \mathrm{cm}^{3}$. The resin is widely used for structure strengthening in China, of which the tensile strength, tensile modulus and elongation are $40 \mathrm{MPa}, 2.5 \mathrm{GPa}$, and $1.80 \%$, respectively. The fiber volume fraction of the specimens was 0.334 .

To investigate the effect of specimen thickness on the water absorption and flexural strength of CFRP laminates, the specimens with 1-ply, 2-ply, 4-ply and 8-ply of carbon fiber sheet (with thickness of $0.5 \mathrm{~mm}, 1 \mathrm{~mm}, 2 \mathrm{~mm}$ and $4 \mathrm{~mm}$, respectively) were prepared for water absorption tests, and the specimens with 2-ply, 4-ply and 8-ply of carbon fiber sheet (with thickness of $1 \mathrm{~mm}, 2 \mathrm{~mm}$ and $4 \mathrm{~mm}$, respectively) were prepared for flexural tests. Standard thickness blocks with thickness of $0.5 \mathrm{~mm}, 1 \mathrm{~mm}, 2 \mathrm{~mm}$ and $4 \mathrm{~mm}$, respectively, were employed to ensure the thickness of specimens. All specimens were prepared by wet lay-up manufacturing process as follows. First, the epoxy and the binder were mixed at the room temperature according to the ratio of 3:1 by weight. After mixed uniformly, a layer of the resin matrix was applied on a glass board. Next, the carbon fiber sheet with a dimension of $300 \mathrm{~mm} \times 300 \mathrm{~mm} \times 0.167 \mathrm{~mm}$ was applied to the glass board and impregnated with the resin matrix. A roller was then used to remove the trapped air bubbles and press the resin to penetrate into the fabric, until the resin was reflected on the surface of the carbon fiber sheet. The aforementioned steps were repeated to fabricate specimens with different plies of carbon fiber sheets. When the required ply of carbon fiber sheets was reached, another glass board was used to cover the specimen with a weight of $30 \mathrm{~kg}$. Before the water absorption and flexural tests, the specimen was cured at ambient room temperature for 30 days, which was much longer than the curing time suggested by the supplier (about 7 days) to ensure a full curing of the resin.

Distilled water and alkaline solution were both adopted to immerse specimens with immersion time up to 180 days. The alkaline solution with $\mathrm{pH}=13.0$ was prepared to simulate the pore solution of concrete according to $\mathrm{ACl}$ 440.3R-04 [39]. Literatures [18], [19], [38] indicated that the accelerating rate increased with the aging 
temperature when the degradation mechanism remained unchanged. Therefore, the aging temperature adopted in previous studies generally varied from 20 to

$60{ }^{\circ} \mathrm{C}$ [20], [21], [22], [23], [24], [25], [26], [27], [28], [29]. In this study, the aging temperature was set as $60^{\circ} \mathrm{C}$ to ensure a better accelerated effect.

\subsection{Water absorption test}

The water absorption of CFRP laminates was evaluated by immersing the specimens in distilled water or alkaline solution, and measuring the water uptake at specific periods. According to ASTM D5229 [40], the laminates were mechanically cut into strips with dimensions of $60 \mathrm{~mm} \times 60 \mathrm{~mm} \times h \mathrm{~mm}$, where $h$ was the specimen thickness. Before testing, the specimen was dried in an oven at $60^{\circ} \mathrm{C}$ for $48 \mathrm{~h}$, cooled down to the room temperature and then weighed to obtain the initial mass, $M_{0}$. The specimen was then immersed in distilled water or alkaline solution for aging test. After a given immersion time, the surface water of the specimens were wiped off using tissue paper and weighed to get the aged mass, $M_{t}$. An analytical balance with an accuracy of $\pm 0.1 \mathrm{mg}$ was adopted to weight the specimens. Water uptake, $\omega$, can be expressed as Eq. (1). The adopted immersion durations of water absorption test were shown in Table 1. For each given immersion time, ten specimens were measured, and the averaged results were adopted in the following analysis.

(1) $\omega=\frac{M_{t}-M_{0}}{M_{0}} \times 100$

Table 1. Aging times adopted in the tests.

\begin{tabular}{|l|l|}
\hline Test type & Exposure time \\
\hline Water absorption & $0 \mathrm{~h}, 1 \mathrm{~h}, 2 \mathrm{~h}, 4 \mathrm{~h}, 8 \mathrm{~h}, 1 \mathrm{~d}, 2 \mathrm{~d}, 4 \mathrm{~d}, 7 \mathrm{~d}, 14 \mathrm{~d}, 28 \mathrm{~d}, 90 \mathrm{~d}, 180 \mathrm{~d}$ \\
\hline Flexural strength & $0 \mathrm{~d}, 7 \mathrm{~d}, 14 \mathrm{~d}, 28 \mathrm{~d}, 90 \mathrm{~d}, 180 \mathrm{~d}$ \\
\hline
\end{tabular}

Note: $h$ and $d$ represent hour and day, respectively.

\subsection{Flexural test}

As suggested in ASTM D7264 [41], the flexural strength of CFRP laminates was determined by three point bending test with a loading rate of $1 \mathrm{~mm} / \mathrm{min}$ (Fig. 1). The dimensions of the specimens adopted in the test were listed in Table 2. The flexural strength, $\sigma$, is calculated by Eq. (2),

(2) $\sigma=\frac{3 P L}{2 b h^{2}}$

where $P$ is the measured load, $L$ is the span, $b$ and $h$ are the width and thickness of the specimen, respectively. The aging durations for flexural specimens are shown in Table 1. For each given aging time, the averaged test results of five specimens were presented in the following analysis.

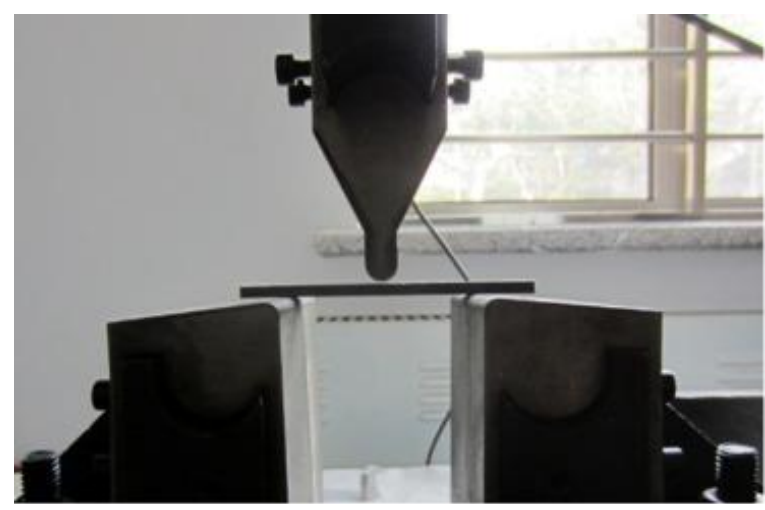

Fig. 1. Three point bending test of CFRP laminates.

Table 2. Dimensions of the specimens (Unit: $\mathrm{mm}$ ). 


\begin{tabular}{|l|l|l|l|}
\hline Geometry & Dimension & & \\
\hline & 2-ply & 4-ply & 8-ply \\
\hline Thickness $h$ & 1 & 2 & 4 \\
\hline Width $b$ & 12.7 & 12.7 & 12.7 \\
\hline Length $L_{0}$ & 50.8 & 50.8 & 100 \\
\hline Span $L$ & 25.4 & 32 & 64 \\
\hline
\end{tabular}

\section{Test results and discussions}

\subsection{Water absorption}

Table 3 shows the tested mean water uptake and CV (coefficient of variation) for each group of specimens. Water uptake curves of CFRP laminates with four thicknesses immersed in distilled water or alkaline solution are shown in Fig. 2. It can be seen that the trend of water uptake curves is composed of ascending and descending phases for both distilled water and alkaline solution. In the ascending branch, water uptake increased almost linearly with the increase of square root of aging time until the peak water uptake is reached. For the specimens with the thicknesses of $0.5 \mathrm{~mm}, 1 \mathrm{~mm}, 2 \mathrm{~mm}$ and $4 \mathrm{~mm}$, the peak water uptakes were $1.07 \%, 0.87 \%, 1.02 \%$ and $1.04 \%$ for distilled water, and were $1.05 \%, 1.11 \%, 1.21 \%$ and $1.10 \%$ for alkaline solution, respectively. It indicates that, for the same solution, the peak water uptakes of CFRP laminates with four thicknesses were almost constant and scarcely influenced by specimen thickness. 
Table 3. Tested water uptake of the CFRP laminates conditioned with distilled water and alkaline solution (Unit: \%)

\begin{tabular}{|c|c|c|c|c|c|c|c|c|c|c|c|c|c|c|c|c|}
\hline $\begin{array}{l}\text { Distilled } \\
\text { water }\end{array}$ & & & & & & & & & $\begin{array}{l}\text { Alkaline } \\
\text { solution }\end{array}$ & & & & & & & \\
\hline & $\begin{array}{l}\boldsymbol{h}=0.5 \\
\mathrm{~mm}\end{array}$ & & $\begin{array}{l}\boldsymbol{h}=1 \\
\mathrm{~mm}\end{array}$ & & $\begin{array}{l}\boldsymbol{h}=2 \\
\mathrm{~mm}\end{array}$ & & $\begin{array}{l}\boldsymbol{h}=4 \\
\mathrm{~mm}\end{array}$ & & $\begin{array}{l}\boldsymbol{h}=0.5 \\
\mathrm{~mm}\end{array}$ & & $\begin{array}{l}\boldsymbol{h}=1 \\
\mathrm{~mm}\end{array}$ & & $\begin{array}{l}\boldsymbol{h}=2 \\
\mathrm{~mm}\end{array}$ & & $\begin{array}{l}\boldsymbol{h}=4 \\
\mathrm{~mm}\end{array}$ & \\
\hline & Mean & $\mathrm{CV}^{+}$ & Mean & $\mathrm{CV}$ & Mean & $\mathrm{CV}$ & Mean & $\mathrm{CV}$ & Mean & $\mathrm{CV}$ & Mean & $\mathrm{CV}$ & Mean & $\mathrm{CV}$ & Mean & $\mathrm{CV}$ \\
\hline 60 & 0.51 & 2.96 & 0.22 & 3.50 & 0.15 & 1.38 & 0.07 & 4.36 & 0.34 & 3.41 & 0.22 & 2.72 & 0.19 & 1.55 & 0.09 & 1.30 \\
\hline 85 & 0.70 & 2.62 & 0.34 & 4.98 & 0.22 & 2.28 & 0.10 & 4.23 & 0.49 & 2.83 & 0.30 & 1.90 & 0.24 & 2.13 & 0.11 & 1.83 \\
\hline 120 & 0.89 & 4.07 & 0.52 & 4.71 & 0.31 & 3.16 & 0.15 & 4.19 & 0.88 & 14.75 & 0.51 & 5.98 & 0.34 & 2.85 & 0.16 & 1.12 \\
\hline 170 & 0.98 & 6.49 & 0.65 & 5.20 & 0.43 & 3.42 & 0.20 & 4.75 & 0.99 & 6.61 & 0.62 & 1.72 & 0.46 & 3.80 & 0.22 & 0.7 \\
\hline 294 & 1.07 & 8.57 & 0.87 & 7.25 & 0.72 & 4.43 & 0.34 & 6.18 & 1.05 & 15.35 & 1.00 & 2.10 & 0.79 & 5.24 & 0.38 & 1.64 \\
\hline 416 & 0.87 & 5.64 & 0.81 & 9.02 & 0.93 & 4.46 & 0.49 & 6.31 & 0.84 & 8.88 & 1.11 & 4.41 & 1.08 & 5.20 & 0.56 & 3.37 \\
\hline 588 & 0.67 & 5.89 & 0.71 & 8.64 & 0.97 & 5.01 & 0.64 & 6.23 & 0.56 & 7.90 & 0.94 & 3.51 & 1.13 & 5.39 & 0.70 & 3.18 \\
\hline 778 & 0.36 & 6.34 & 0.60 & 8.24 & 1.02 & 6.27 & 0.85 & 6.18 & 0.13 & 7.01 & 0.68 & 3.28 & 1.21 & 6.80 & 0.91 & 3.43 \\
\hline 1100 & 0.11 & 4.39 & 0.47 & 7.49 & 0.99 & 6.45 & 1.04 & 6.48 & -0.28 & 2.19 & 0.36 & 4.35 & 1.12 & 6.95 & 1.11 & 3.90 \\
\hline 1610 & -0.52 & 7.12 & 0.30 & 6.51 & 0.88 & 8.41 & 1.04 & 10.52 & -1.27 & 5.61 & 0.14 & 8.04 & 0.95 & 10.61 & 1.09 & 4.74 \\
\hline 2789 & -1.54 & 25.41 & 0.04 & 3.23 & 0.49 & 26.88 & 0.91 & 10.79 & -2.94 & 18.40 & -0.88 & 6.63 & 0.71 & 11.03 & 0.95 & 6.34 \\
\hline 3944 & -2.18 & 14.63 & -0.85 & 10.63 & 0.15 & 21.60 & 0.74 & 15.10 & -4.26 & 24.29 & -1.90 & 9.05 & 0.47 & 4.53 & 0.88 & 16.00 \\
\hline
\end{tabular}

+Coefficient of variation 


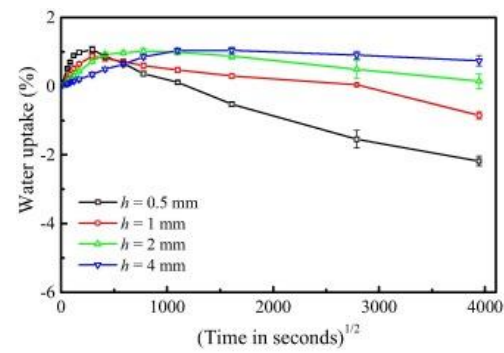

(a)

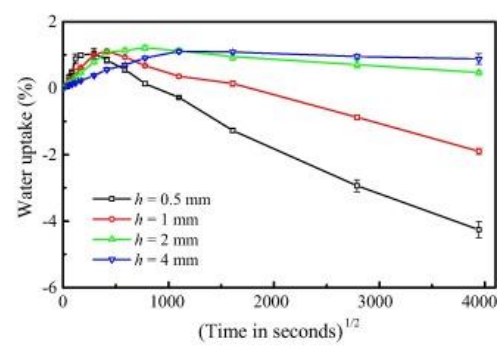

(b)

Fig. 2. Water uptake vs. aging time for the specimens with different thicknesses immersed in (a) distilled water or (b) alkaline solution.

In the descending branch, water uptake decreased with the increase of square root of aging time. At the aging time of 180 days, as specimen thickness varied from $0.5 \mathrm{~mm}$ to $4 \mathrm{~mm}$, water uptakes were $-2.18 \%,-0.84 \%$, $0.15 \%$ and $0.74 \%$ for distilled water, and were $-4.26 \%,-1.89 \%, 0.47 \%$ and $0.87 \%$ for alkaline solution, respectively. It should be noted that the measured mass of CFRP laminates with the thickness of $0.5 \mathrm{~mm}$ and $1 \mathrm{~mm}$ at 180 day was smaller than the initial one. This observation is not consistent with usual test results, in which the initial linear increase of water uptake is followed by another stage of linear increase with a reduced slope (i.e., the two-stage diffusion response) [23], [24], [25]. It is well known that the carbon fiber hardly absorbs water during immersion, and thus water uptake of CFRP laminates is mainly contributed by water uptake of resin matrix [20], [21], [23]. Therefore, the decrease of water uptake can be explained with the degradation processof resins in the aging. The SEM images in Fig. 3 show that the corrosive environment at $60{ }^{\circ} \mathrm{C}$ degraded the resin matrix structure and accelerated the hydrolysis of the resin in this study. The SEM image of the original specimen $(h=2 \mathrm{~mm})$ is compared with those of the aged ones. After the 180-day conditioning in distilled water or alkaline solution, parts of resins became rough in the surface, which suggests that a severe hydrolysis had happened to these regions. The hydrolysis of resins generated more spaces inside the CFRP laminates, which was then filled with test solutions. Since the density of resins is much greater than that of solutions, however, the tested water uptake by weight showed decreasing as the hydrolysis of resins progressed. Besides the SEM images, this deduction can also be supported by literature [42], which suggested that the mass loss of resin at long-time exposure could be attributed to chemical degradation such as leaching and hydrolysis.

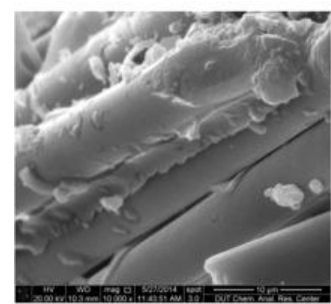

(a)

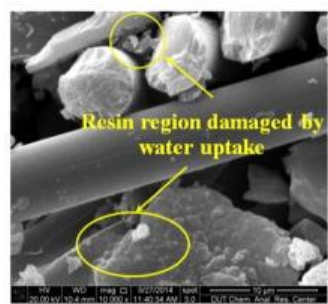

(b)

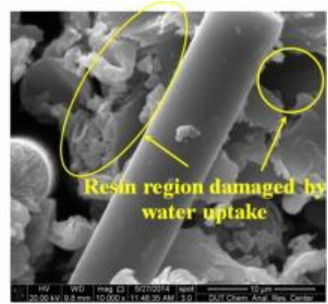

(c)

Fig. 3. SEM images of (a) original specimen; (b) specimen immersed in $60^{\circ} \mathrm{C}$ distilled water after 180 days; (c) specimen immersed in $60^{\circ} \mathrm{C}$ alkaline solution after 180 days.

\subsection{Flexural strength retention}

Table 4 shows the tested mean flexural strength retention and CV (coefficient of variation) for each group of specimens. The flexural strength retentions of CFRP laminates immersed in distilled water or alkaline solution are plotted against aging times (in day) in Fig. 4. It is shown in the figure that the flexural strength retention decreased gradually with the increase of aging time, and then remained relatively constant for the specimens 
with thicknesses of $2 \mathrm{~mm}$ and $4 \mathrm{~mm}$. For the specimens with thickness of $1 \mathrm{~mm}$, however, the flexural strength retention decreased rapidly in the first week and followed with an apparent recovery. Apparent reductions were generated in flexural strengths after a long aging time for all specimens tested in this study. For the specimens with thicknesses of $1 \mathrm{~mm}, 2 \mathrm{~mm}$ and $4 \mathrm{~mm}$, flexural strength retentions at 180 days were 66.6\%, 70.4\%, 71.9\% for the distilled water, respectively, and were $65.5 \%, 75.0 \%, 75.6 \%$ for the alkaline solution, respectively.

Table 4. Tested flexural strength retention of the CFRP laminates conditioned with distilled water and alkaline solution (Unit: \%).

\begin{tabular}{|c|c|c|c|c|c|c|c|c|c|c|c|c|}
\hline Duration & $\begin{array}{l}\text { Distilled } \\
\text { water }\end{array}$ & & & & & & $\begin{array}{l}\text { Alkaline } \\
\text { solution }\end{array}$ & & & & & \\
\hline (Day) & $\begin{array}{l}h=1 \\
\mathrm{~mm}\end{array}$ & & $\begin{array}{l}h=2 \\
\mathrm{~mm}\end{array}$ & & $\begin{array}{l}h=4 \\
\mathrm{~mm}\end{array}$ & & $\begin{array}{l}h=1 \\
\mathrm{~mm}\end{array}$ & & $\begin{array}{l}h=2 \\
\mathrm{~mm}\end{array}$ & & $\begin{array}{l}h=4 \\
\mathrm{~mm}\end{array}$ & \\
\hline & Mean & $\mathrm{CV}^{+}$ & Mean & CV & Mean & CV & Mean & CV & Mean & CV & Mean & CV \\
\hline 7 & 54.79 & 1.46 & 75.02 & 1.80 & 90.90 & 1.17 & 66.41 & 1.82 & 89.10 & 1.22 & 95.18 & 1.42 \\
\hline 14 & 67.63 & 0.97 & 79.94 & 0.94 & 85.93 & 1.92 & 68.58 & 0.86 & 83.55 & 1.94 & 93.58 & 0.93 \\
\hline 30 & 66.58 & 1.41 & 70.37 & 1.23 & 78.04 & 1.46 & 74.51 & 1.18 & 82.65 & 1.39 & 78.67 & 1.39 \\
\hline 90 & 71.08 & 1.22 & 75.06 & 1.94 & 71.93 & 1.12 & 66.96 & 1.91 & 74.95 & 1.10 & 80.27 & 1.21 \\
\hline 180 & 68.49 & 1.74 & 75.41 & 1.38 & 79.27 & 1.31 & 65.46 & 1.42 & 80.42 & 1.33 & 76.56 & 1.75 \\
\hline
\end{tabular}

+Coefficient of variation.

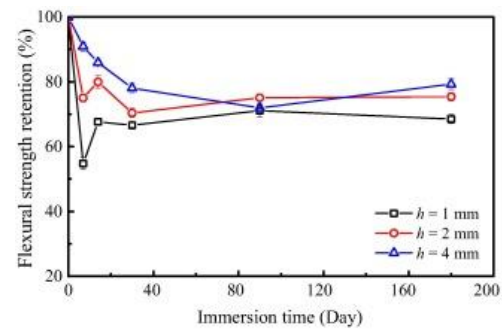

(a)

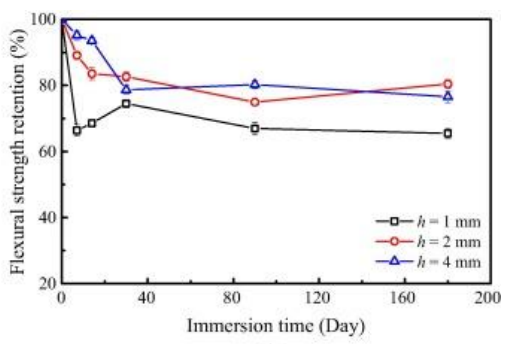

(b)

Fig. 4. Flexural strength retention vs. aging time for the specimens with different thicknesses immersed in (a) distilled water, and (b) alkaline solution.

Hong et al. [25] reported that water immersion had little effect on tensile strength of pultruded CFRP plates. It is because that the tensile strength of pultruded CFRP composites is mainly dependent on the property of carbon fiber. Carbon fiber is hardly corroded and thus its tensile strength is scarcely affected by hygrothemal aging effect. In this study, however, the effect of hygrothemal aging on the flexural strength of CFRP laminates is remarkable. The observation is consistent with the findings in literature [29], which suggested the tensile strength of wet lay-up CFRP laminates could decrease by $30 \%$ after duration of 30 weeks. The significant degradation of flexural strength should be attributed to the debonding between the fiber and the resin matrix. It is recognized that the fiber-resin matrix adhesion also affects the flexural strength of CFRP composites besides of the fiber reinforcement [15], [17]. Sufficient fiber-resin matrix adhesion ensures a reliable bond between the carbon fiber and the epoxy resin matrix, by which the strength of the carbon fiber could be fully utilized. Under harsh environmental conditions, the fiber-resin adhesion is prone to be weakened due to the degradation of epoxy resins as shown in Fig. 3, which further results in a debonding between the fiber and the resin matrix. This deduction can also be supported by Fig. 5 , which shows the SEM images of the CFRP specimen $(h=2 \mathrm{~mm})$ before and after aging. It is observed that the resin matrix was greatly corroded after an aging time of 180 days. Therefore, the fiber-resin adhesion was weakened in some regions. With such effect, partial debonding occurred and local weaknesses were generated in CFRP laminates. When the specimens were subjected to the bending load, the compatibility between the fiber and resin matrix of the specimens could not be guaranteed at these 
weak regions, which resulted in a premature failure of the specimens before the strength of carbon fiber was fully used.

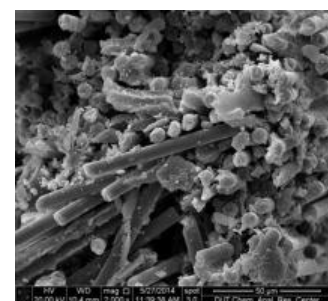

(a)

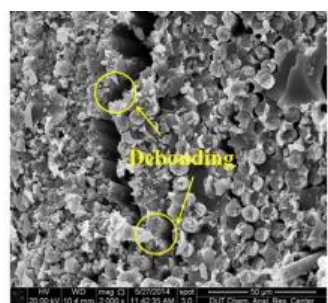

(b)

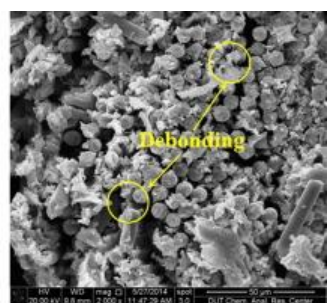

(c)

Fig. 5. SEM images of the fractured section of (a) original specimen; (b) specimen immersed in $60{ }^{\circ} \mathrm{C}$ distilled water after 180 days; (c) specimen immersed in $60^{\circ} \mathrm{C}$ alkaline solution after 180 days.

\subsection{The effect of specimen thickness}

Water uptakes of CFRP laminates for different aging durations are shown in Fig. 6, Fig. 7, Fig. 8. Fig. 6 shows that, in the early stage of immersion ( $1-8 \mathrm{~h}$ ), the smaller the thickness was, the higher water uptake of CFRP laminates was for the same aging time. The trend was opposite in the later stage of immersion (14-180 days) as shown in Fig. 8. For the middle stage of immersion (2-8 days), Fig. 7 shows that the water uptake of CFRP laminates increased first and then decreased with the increase of specimen thickness. These results indicate that the specimen thickness has different effects on the water uptake of CFRP laminates for different aging times. In addition, it can be seen from Fig. 6, Fig. 8 that the change rate of water uptake decreased with the increase of specimen thickness for the same aging time, i.e., the difference among water uptakes of CFRP laminates was smaller with the increase of specimen thickness.

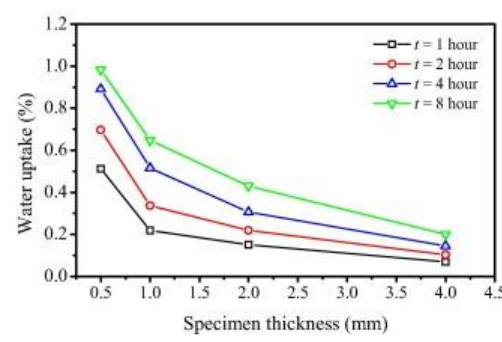

(a)

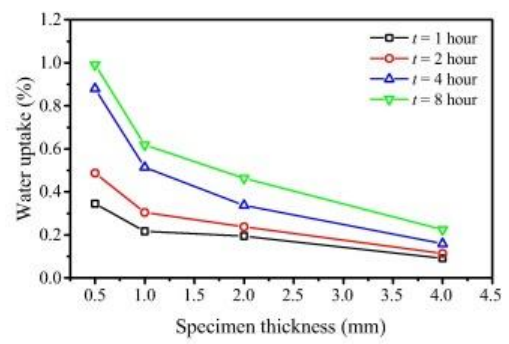

(b)

Fig. 6. Effect of specimen thickness on water uptake in the early stage of immersion in (a) distilled water or (b) alkaline solution.

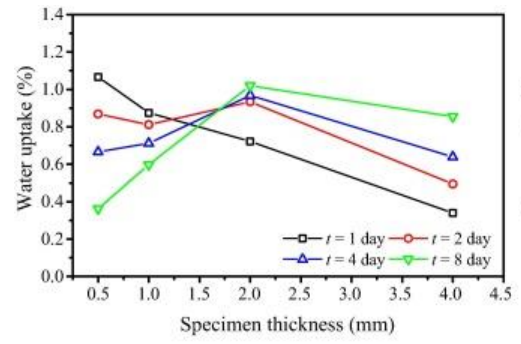

(a)

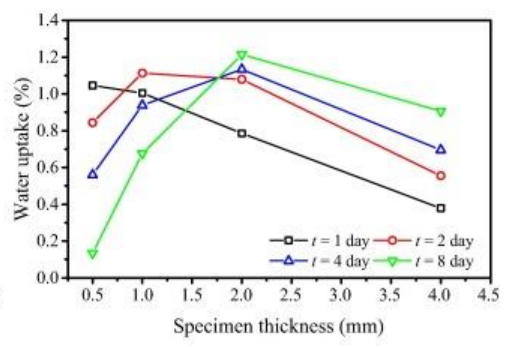

(b)

Fig. 7. Effect of specimen thickness on water uptake in the middle stage of immersion in (a) distilled water or (b) alkaline solution. 


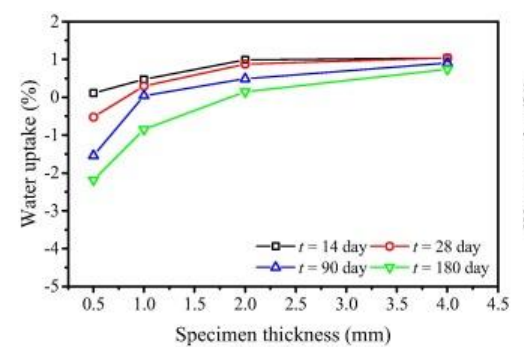

(a)

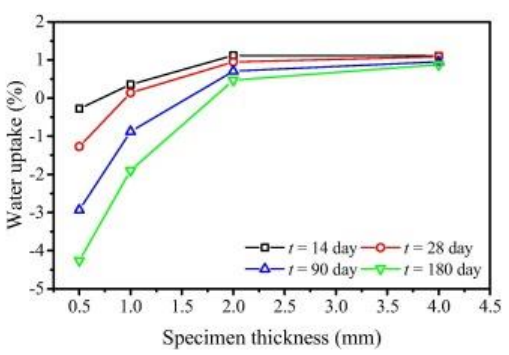

(b)

Fig. 8. Effect of the specimen thickness on water uptake in the later stage of immersion in (a) distilled water or (b) alkaline solution.

The relationship between flexural strength retention and specimen thickness is shown in Fig. 9 for different aging times. It can be seen that thicker specimens had larger strength retention for most cases. This observation suggests that the specimen with a smaller thickness is more likely to be eroded for a given aging time. On the other hand, for some cases (e.g., $t=90$ days for distilled water, $t=28$ and 180 days for alkaline solution), no significant law can be drawn for flexural strength retentions of specimens with different thicknesses. This can be explained by the scatter of test data because only three thicknesses were adopted as the test variables in this study. Moreover, the flexural strength was greatly influenced by the interfacial properties of fiber and resin. Therefore the possible non-uniformly debonding of the fiber as shown in Fig. 5 could lead to an abnormal change of flexural strength shown in Fig. 9.

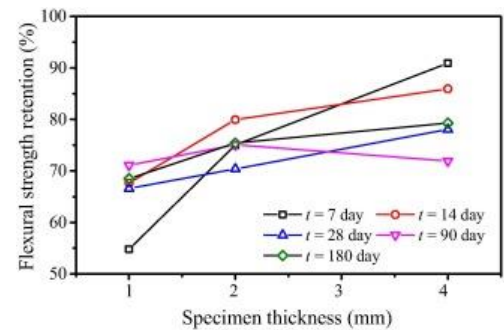

(a)

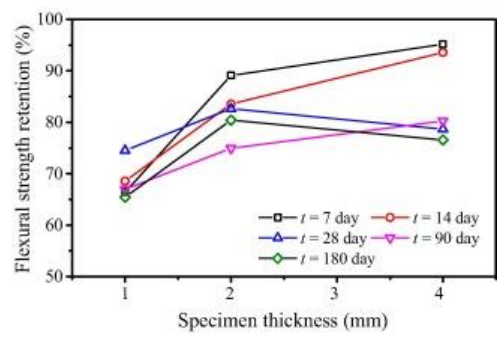

(b)

Fig. 9. Effect of specimen thickness on flexural strength retention of CFRP laminates immersed in (a) distilled water or (b) alkaline solution.

\section{Analytical model of accelerated factors}

The above test results clearly show that the specimen thickness has great influences on both water absorption and flexural strength of CFRP laminates. It can be seen from Fig. 2, Fig. 4 that different aging times are needed to achieve the same level of water uptake or flexural strength retention for CFRP laminates with different thicknesses. Hence, it is possible to accelerate the aging effect on CFRP laminates by changing the specimen thickness. In this section, such effect is quantitatively evaluated in a theoretical manner, and analytical models of accelerated factors considering the effect of specimen thickness for aging tests with different aging times are developed. In this study, the accelerated factor is defined as the ratio of the durations needed to reach the same level of water uptake or flexural strength retention for the specimens with different thicknesses.

\subsection{Accelerated factor for water absorption}

Typical relationships between water uptake and aging time are shown in Fig. 10(a) and (b) for Fickian and nonFickian CFRP laminate specimens with different thicknesses, respectively [19]. For a given specimen thickness, Fig. 10(a) shows that the water uptake of Fickian model, $\omega(t)_{F}$, first nonlinearly increases with the aging time, then gradually reaches a quasi-equilibrium level, $\omega_{m}$, and afterwards remains constant. The 
diffusion of the Fickian model is assumed to be determined by the concentration gradient of the aging condition, and complies with the classic Fick's law, as shown in Eq. (3) [19].

(3) $\omega(t)_{\mathrm{F}}=\omega_{m}\left\{1-\exp \left[-7.3\left(\frac{D t}{h^{2}}\right)^{0.75}\right]\right\}$

where $\omega(t)_{\mathrm{F}}$ is the water uptake of Fickian specimens at aging time $t, \omega_{m}$ is the quasi-equilibrium water uptake, and $h$ is the thickness of the specimen. If the Fickian specimens with two thicknesses, i.e., $h_{1}$ and $h_{2}$, are tested to reach the same water uptake after aging time $t_{1}$ and $t_{2}$ immersed in identical condition, a balanced equation can be obtained as

(4) $\omega\left(t_{1}\right)_{\mathrm{F}}=\omega_{m}\left\{1-\exp \left[-7.3\left(\frac{D t_{1}}{h_{1}^{2}}\right)^{0.75}\right]\right\}=\omega\left(t_{2}\right)_{\mathrm{F}}=\omega_{m}\left\{1-\exp \left[-7.3\left(\frac{D t_{2}}{h_{2}^{2}}\right)^{0.75}\right]\right\}$

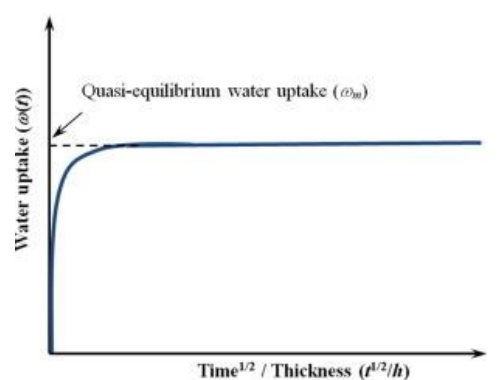

(a)

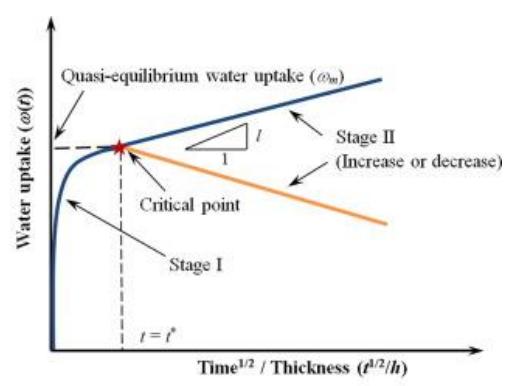

(b)

Fig. 10. Typical model of water uptake for composites: (a) Fickian; (b) non-Fickian.

Ref. [19] reported that the parameters of $\omega_{m}$ and $D$ in Eq. (4) are generally constant for a given resin matrix and immersion solution. This means that the water uptake changed by aging time is determined by the specimen thickness $h$. For the Fickian specimens with different thicknesses, the aging times needed to reach a same water uptake should satisfy

(5) $t_{1} / t_{2}=\left(h_{1} / h_{2}\right)^{2}$

On the other hand, as shown in Fig. 10(b), the trend of water absorption of non-Fickian specimen can be divided into two stages. In Stage I, the water uptake, $\omega(t)_{\mathrm{FN}, \mathrm{I}}$, increases nonlinearly with the aging time before a critical point at the aging time $t=t^{*}$. In this stage, the diffusion of non-Fickian specimens is identical with that of Fickian ones. After that, the water uptake in Stage II, $\omega(\mathrm{t})_{\mathrm{FN}, \mathrm{II}}$, increases or decreases linearly with the aging time, which is related to the types of resin matrices and immersion solutions. For non-Fickian specimens with two thicknesses, i.e., $h_{1}$ and $h_{2}$, the aging times $\left(t_{1}^{*}\right.$ and $\left.t_{2}^{*}\right)$ needed to reach the same water uptake before the critical point, are also dependent on their thicknesses, and can be determined with Eq. (5), i.e.,

(6) $t_{1}^{*} / t_{2}^{*}=\left(h_{1} / h_{2}\right)^{2}$

After the critical point, a linear relationship between the water uptake in stage $\mathrm{II}, \omega(t)_{\mathrm{FN}, I I}$, and the aging time increment, $\Delta \mathrm{t}$, can be established as Eq. (7).

(7) $\omega(t)_{\mathrm{NF}, \mathrm{II}}=\omega_{m}+l \cdot \frac{\sqrt{\Delta t}}{h}$

where $/$ is the slope of water uptake curve shown in Fig. 10(b).

If the specimens with two thicknesses $\left(h_{1}\right.$ and $\left.h_{2}\right)$ are immersed in identical condition with incremental aging times $\left(\Delta \mathrm{t}_{1}\right.$ and $\left.\Delta \mathrm{t}_{2}\right)$ to achieve a given water uptake, a balanced equation can also be established in the stage similar to Stage I, which is given as 
(8) $\omega\left(t_{1}\right)_{\mathrm{NF}, \mathrm{II}}=\omega_{m}+l \cdot \frac{\sqrt{\Delta t_{1}}}{h_{1}}=\omega\left(t_{2}\right)_{\mathrm{NF}, \mathrm{II}}=\omega_{m}+l \cdot \frac{\sqrt{\Delta t_{2}}}{h_{2}}$

Since the parameters, $\omega_{m}$ and $I$, are both constants for a given immersion condition, which are irrelevant to the specimen thickness $h$ [19], Eq. (8) can be re-written as

(9) $\Delta t_{1} / \Delta t_{2}=\left(h_{1} / h_{2}\right)^{2}$

Therefore, the total time for non-Fickian specimens with two thicknesses to reach a same water uptake during Stages I and II can be expressed as

(10) $\frac{t_{1}}{t_{2}}=\frac{t_{1}^{*}+\Delta t_{1}}{t_{2}^{*}+\Delta t_{2}}=\left(\frac{h_{1}}{h_{2}}\right)^{2}$

At last, the acceleration factor of water uptakes can be calculated with Eq. (5) and Eq. (10) for Fickian and nonFickian specimens, respectively.

\subsection{Accelerated factor for flexural strength retention}

In order to simplify the analysis, CFRP laminates immersed in corrosive solutions are assumed to suffer a doublesurface uniform corrosionalong the direction of the thickness (shown in Fig. 11(a)). Assuming the corrosion rate keeps constant, the total corrosion depth reaches a value of $x$ at the top and bottom surfaces of the specimen after a given aging time. It is well known that the corrosion condition affects the bond between carbon fiber and epoxy resin matrix, which further leads to a decrease in tensile strength of CFRP laminates at corroded regions after an aging time. Fig. 11(b) shows stress distribution in a cross-section of the partially corroded specimen subjected to a bending moment, where $\sigma_{0}$ and $\sigma_{e}$ denote the initial and residual tensile strengths of the specimen, respectively. It can be deduced that the resisting moment of the section, $M(t)$, can be expressed by Eq. (11).

(11) $M(t)=2 b\left[\sigma_{e} \cdot \frac{x}{2} \cdot\left(\frac{h}{2}-\frac{x}{4}\right)+\frac{1}{4} \sigma_{0} \cdot\left(\frac{h}{2}-\frac{x}{2}\right)^{2}\right]$

where $b$ and $h$ are the width and thickness of the specimen, respectively.

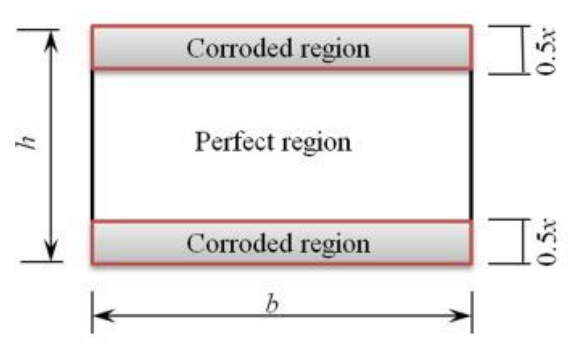

(a)

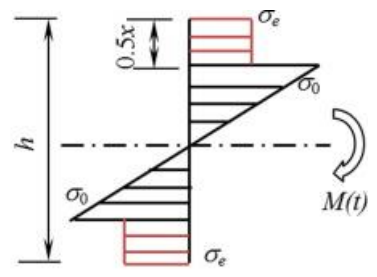

(b)

Fig. 11. Sectional schematic of the specimen for flexural strength test: (a) Double-surface corrosion; (b) Crosssectional stress distribution.

Therefore, the time-dependent nominal flexural strength, $\sigma(t)$, can be obtained as

(12) $\sigma(t)=\frac{6 M(t)}{b h^{2}}=3\left(\sigma_{0}-\sigma_{e}\right)\left[\frac{1}{2}\left(\frac{x}{h}\right)^{2}-\frac{x}{h}\right]+\frac{3}{2} \sigma_{0}$

According to literatures [43], [44], [45], [46], for the layer-forming type corrosion as shown in Fig. 11, the corrosion depth of the specimen, $x$, can be expressed in the term of aging time, $t$, as Eq. (13).

(13) $x=\alpha \sqrt{t}$ 
where $\alpha$ is the material constant and independent of $h$.

Literatures [21], [23], [24], [25], [26] suggested that, for a given epoxy resin and carbon fiber, the residual tensile strength, $\sigma_{e}$, is irrelevant to the specimen thickness, and remains basically a constant after a long duration. Substituting Eq. (13) into Eq. (12), the nominal flexural strength of CFRP laminate is given by:

(14) $\sigma(t)=3\left(\sigma_{0}-\sigma_{e}\right)\left[\frac{1}{2} \alpha^{2}\left(\frac{\sqrt{t}}{h}\right)^{2}-\frac{\sqrt{t}}{h}\right]+\frac{3}{2} \sigma_{0}$

Considering CFRP specimens with two thicknesses, i.e., $h_{1}$ and $h_{2}$, are tested to achieve the identical nominal flexural strength after aging times $t_{1}$ and $t_{2}$, respectively, Eq. (15) can be obtained.

(15) $\sigma\left(t_{1}\right)=3\left(\sigma_{0}-\sigma_{e}\right)\left[\frac{1}{2} \alpha^{2}\left(\frac{\sqrt{t_{1}}}{h_{1}}\right)^{2}-\frac{\sqrt{t_{1}}}{h_{1}}\right]+\frac{3}{2} \sigma_{0}=\sigma\left(t_{2}\right)=3\left(\sigma_{0}-\sigma_{e}\right)\left[\frac{1}{2} \alpha^{2}\left(\frac{\sqrt{t_{2}}}{h_{2}}\right)^{2}-\frac{\sqrt{t_{2}}}{h_{2}}\right]+\frac{3}{2} \sigma_{0}$

Eq. (15) is valid when the aging times $t_{1}$ and $t_{2}$ satisfy the case that $t_{1} / t_{2}=\left(h_{1} / h_{2}\right)^{2}$, which indicates that the acceleration factor of flexural strength retention (the ratio of strengths after and before aging) of CFRP laminates subjected to hygrothermal aging can be calculated with Eq. (5).

It is shown from the above analysis that, for CFRP laminate specimens with two thicknesses, the ratio of required aging times to reach a given water uptake and/or flexural strength retention is directly proportional to the square of their thickness ratio. Therefore, it is feasible to accelerate the aging time by reducing the specimen thickness.

\section{Model validation}

The analytical results suggest that a thicker specimen needs more aging time to reach a given water uptake and/or flexural strength retention. The water uptake or flexural strength retention after aging is positively correlated to the ratio of aging time and square of thickness, i.e.,

(16) $k \frac{t}{h^{2}}=c$

where $t$ is the aging time, $h$ is the thickness of CFRP specimens, $k$ is the proportionality factor, and $c$ is the water uptake or flexural strength retention of CFRP laminates after aging. For the same immersion solution and test temperature, the proportionality factor, $k$, keeps a constant. For the CFRP laminates used this study, Fig. 2 shows that the trend of water uptake follows two stages, thus $k$ should be positive and negative constants for ascending and descending stages, respectively.

It can be seen from Eq. (16) that the water uptake and/or flexural strength retention of CFRP specimens should be proportional to the inverse of square of specimen thickness for a given aging time. To verify the analytical model, therefore, linear fittings are developed between the tested water uptake or flexural strength retention and $1 / h^{2}$, respectively.

It can be seen from Figs. 12 and 13 that, the water uptake increases and decreases as $1 / \mathrm{h}^{2}$ increases for ascending and descending stages of the absorption response of CFRP laminates, respectively. Because the proportionality factors, $k$, remain positive and negative constants for ascending and descending branches respectively, water uptakes are basically linear functions of $1 / \mathrm{h}^{2}$ in the two stages. In addition to water uptakes, the fitting results of flexural strength retentions are shown in Fig. 14 for different aging times. It is shown that the flexural strength retention is generally proportional to $1 / \mathrm{h}^{2}$ despite of the dispersed test data for some cases, e.g., $t=28$ days for distilled water and alkaline solution. 


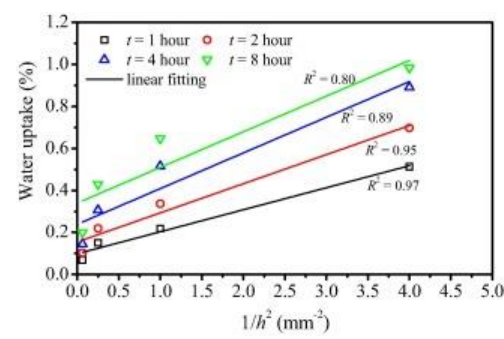

(a)

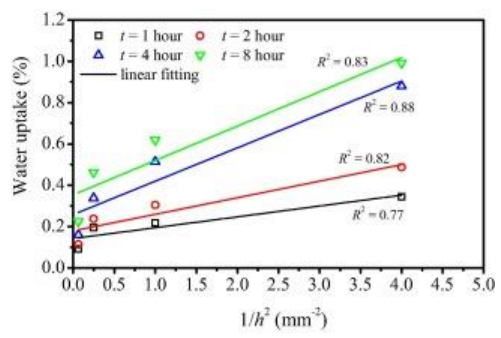

(b)

Fig. 12. Linear fitting results between water uptake and $1 / \mathrm{h}^{2}$ in ascending branch for: (a) distilled water; (b) alkaline solution.

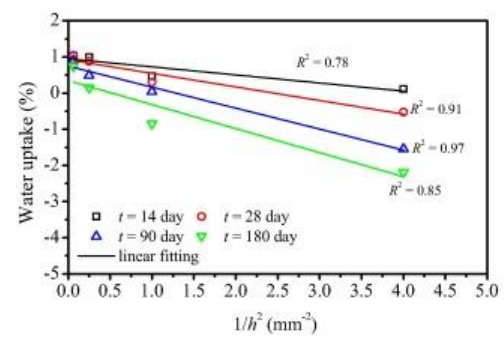

(a)

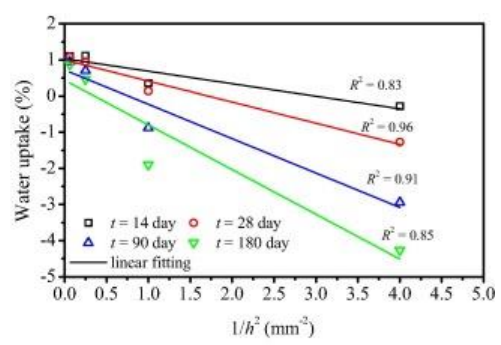

(b)

Fig. 13. Linear fitting results between water uptake and $1 / \mathrm{h}^{2}$ in descending branch for: (a) distilled water; (b) alkaline solution.

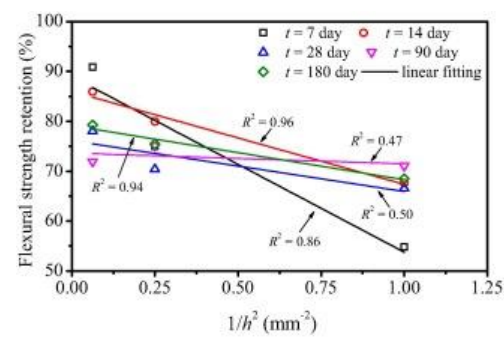

(a)

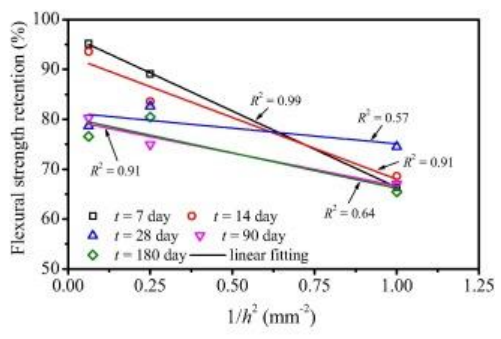

(b)

Fig. 14. Linear fitting results between flexural strength retention and $1 / h^{2}$ for: (a) distilled water; (b) alkaline solution.

According to Eq. (5), the acceleration factors were calculated as 1, 4, and 16 for specimens with the thicknesses of $4 \mathrm{~mm}, 2 \mathrm{~mm}$ and $1 \mathrm{~mm}$, respectively. Then test results of water uptakes and flexural strength retentions (i.e., Figs. 2 and 4) were transformed by multiplying aging times for $1 \mathrm{~mm}$ and $2 \mathrm{~mm}$ specimens with corresponding acceleration factors, and shown in Figs. 15 and 16, respectively. It should be noted that, based on the proposed model, an aging time up to 8 years is covered by test data in this study for both water uptakes and flexural strength retentions of CFRP laminates. Based on the transformed test data of the specimen with the thickness of $1 \mathrm{~mm}$, the long-term predictions for water uptakes and flexural strength retentions are obtained by regression and shown in Figs. 15 and 16, which indicate that the prediction results agree well with the transformed test data for all thicknesses. 


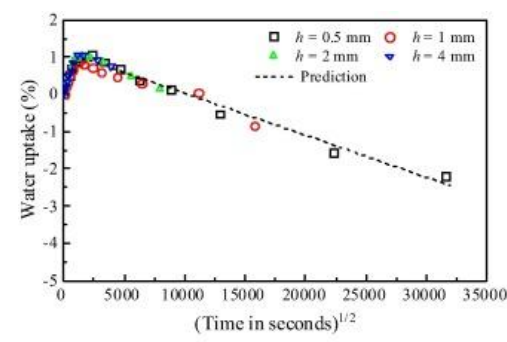

(a)

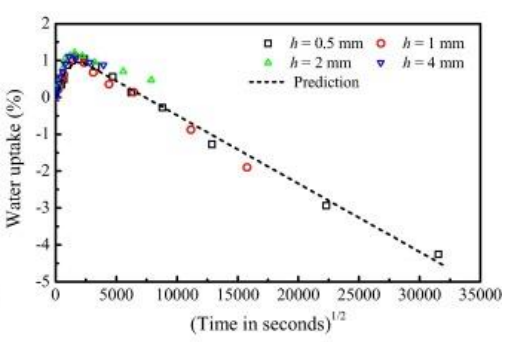

(b)

Fig. 15. Transformed results of water uptakes by the proposed model for: (a) distilled water; (b) alkaline solution.

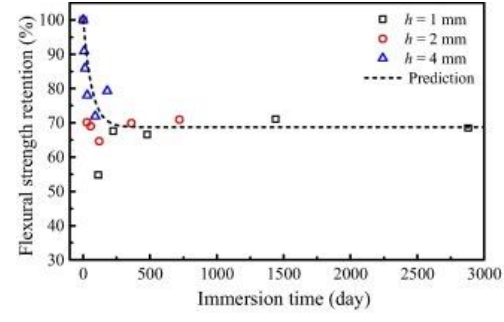

(a)

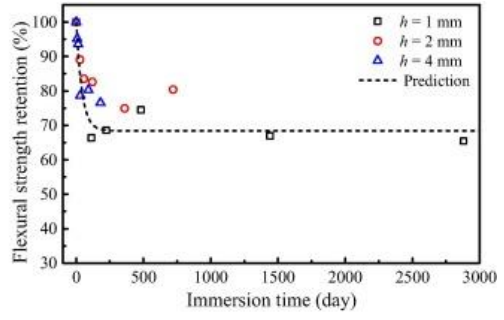

(b)

Fig. 16. Transformed results of flexural strength retention by the proposed model for: (a) distilled water; (b) alkaline solution.

It can be seen from the predicting procedures that the application of the proposed model is much easier than TAM. It is mainly because that the activation energy must be determined when using TAM, and thus an additional regression analysis of test data is inevitable. Since the activation energy of TAM is calculated from test data, test results corresponding to at least three different temperatures should be provided [38]. This implies that TAM is inappropriate to be used in test programs with less than three temperatures [36], [37]. Comparatively, the acceleration factor calculated based on the proposed model is only related to the thickness of the specimen, and thus can be easily used for wider range.

\section{Conclusions}

In this study, the effect of specimen thickness on the water absorption and flexural strength of wet lay-up CFRP laminates immersed in distilled water or alkaline solution was investigated. An analytical study was developed to deduce the accelerated factor of the thickness-based accelerated method for hygrothermal aging of the CFRP laminates. Based on the results, the following conclusions can be drawn.

1. In this study, the trend of water uptake of the wet lay-up CFRP laminates conditioned in distilled water or alkaline solution can be divided into two stages. In the early stage of immersion, the water uptake increased with the aging time until the peak water uptake was reached. After that, the water uptake decreased with the increase of aging time for some cases, which could be caused by the hydrolysis of the resin. To further research the factors (aging temperature, resin and/or solution type, etc.,) influencing the degradation mechanism, more studies are still needed in the future.

2. The water uptakes and flexural strength retentions of wet lay-up CFRP laminates were greatly affected by the adopted specimen thicknesses. For CFRP laminates conditioned in distilled water or alkaline solution up to a duration of 180 days, the water uptake decreased in the early stage of immersion and increased in the later stage of immersion with the increase of specimen thickness. Meanwhile, the flexural strength retention generally increased as the specimen thickness increased. In the future, the direct tensile test is still needed to investigate the mechanical properties of aged CFRP laminates. 
3. The model of accelerated factors for the proposed thickness-based accelerated method, which was expressed as the ratios of square of specimen thicknesses, was developed for water uptakes and flexural strength retentions of CFRP laminates. The model was verified with the current test results, and applied to predict the long-term properties of the wet lay-up CFRP laminates. The results showed that the proposed model was easy for application and in a good agreement with test data.

\section{Conflict of interest}

The authors declared that there are no conflicts of interest.

\section{Acknowledgements}

The financial supports from the National Key R\&D Program of Chinawith Grant No. 2017YFC0703000, the National Natural Science Foundation of China with Grant Nos. 51878120 and 51778102, the Fundamental Research Funds for the Central Universities with Grant No. DUT18LK35, the Natural Science Foundation of Liaoning Province of China with Grant No. 20180550763, are greatly acknowledged.

\section{References}

[1] Y. Huang, Y. Guo, Review of durability of Fiber Reinforced Polymer (FRP) reinforced concrete structure. Appl. Mech. Mater., 548-549 (2014), pp. 1651-1654

[2] J.G. Teng, G. Lin, T. Yu, Analysis-oriented stress-strain model for concrete under combined FRP-steel confinement. J. Compos. Constr., 19 (5) (2015), p. 04014084

[3] Y. Wang, Y. Wang, B. Wan, B. Han, G. Cai, R. Chang, Strain and damage self-sensing of basalt fiber reinforced polymer laminates fabricated with carbon nanofibers/epoxy composites under tension. Composites Part A, 113 (2018), pp. 40-52

[4] Q. Cao, J. Tao, Z. Wu, Z.J. Ma, Behavior of FRP-steel confined concrete tubular columns made of expansive self-consolidating concrete under axial compression. J. Compos. Constr., 21 (5) (2017), p. 04017037

[5] J. Dai, Y. Bai, J.G. Teng, Behavior and modeling of concrete confined with FRP composites of large deformability. J. Compos. Constr., 15 (6) (2011), pp. 963-973

[6] T. Mohammadi, B. Wan, K.A. Harries, M.E. Sweriduk, Bond behavior of FRP-concrete in presence of intermediate crack debonding failure. J. Compos. Constr., 21 (5) (2017), p. 4017018

[7] Y. Bai, J. Dai, J.G. Teng, Buckling of steel reinforcing bars in FRP-confined RC columns: an experimental study. Constr. Build. Mater., 140 (2017), pp. 403-415

[8] G. Lin, T. Yu, J.G. Teng, Design-oriented stress-strain model for concrete under combined FRP-steel confinement. J. Compos. Constr., 20 (4) (2015), p. 04015084

[9] Z. Lu, G. Xian, H. Li, Effects of elevated temperatures on the mechanical properties of basalt fibers and BFRP plates. Constr. Build. Mater., 127 (2016), pp. 1029-1036

[10] Z. Yang, H. Wang, X. Ma, F. Shang, Y. Ma, Z. Shao, et al., Flexural creep tests and long-term mechanical behavior of fiber-reinforced polymeric composite tubes. Compos. Struct., 193 (2018), pp. 154-164

[11] G. Lin, J.G. Teng, Three-dimensional finite element analysis of FRP-confined circular concrete columns under eccentric loading. J. Compos. Constr., 21 (4) (2017), p. 04017003

[12] Q. Cao, J. Tao, Z.J. Ma, Z. Wu, Axial compressive behavior of CFRP confined expansive concrete columns. ACI Struct. J., 114 (2) (2017), pp. 475-485

[13] Y. Pan, G. Xian, M.A.G. Silva, Effects of water immersion on the bond behavior between CFRP plates and concrete substrate. Constr. Build. Mater., 101 (1) (2015), pp. 326-337

[14] W. Jun, G. Hota, L. Ruifeng, L. Weiqing, Durability and prediction models of fiber-reinforced polymer composites under various environmental conditions: a critical review. J. Reinf. Plast. Comp., 35 (3) (2015), pp. 179-211

[15] Z. Wang, G. Xian, X. Zhao, Effects of hydrothermal aging on carbon fibre/epoxy composites with different interfacial bonding strength. Constr. Build. Mater., 161 (2018), pp. 634-648 
[16] D. Zhang, X. Gu, Q. Yu, H. Huang, B. Wan, C. Jiang, Fully probabilistic analysis of FRP-to-concrete bonded joints considering model uncertainty. Compos. Struct., 185 (2018), pp. 786-806

[17] S. Alessi, G. Pitarresi, G. Spadaro, Effect of hydrothermal ageing on the thermal and delamination fracture behaviour of CFRP composites. Composites Part B, 67 (2014), pp. 145-153

[18] M. Zoghi, The International Handbook of FRP Composites in Civil Engineering. CRC Press, Florida, United States (2013)

[19] L.R. Bao, A.F. Yee, Effect of temperature on moisture absorption in a bismaleimide resin and its carbon fiber composites. Polymer, 43 (2002), pp. 3987-3997

[20] V.M. Karbhari, G. Xian, Hygrothermal effects on high VF pultruded unidirectional carbon/epoxy composites: moisture uptake. Compos. B Eng., 40 (1) (2009), pp. 41-49

[21] I. Kafodya, G. Xian, H. Li, Durability study of pultruded CFRP plates immersed in water and seawater under sustained bending: water uptake and effects on the mechanical properties. Composites Part

B, 70 (2015), pp. 138-148

[22] J.H.S. Almeida, S.D.B. Souza, E.C. Botelho, S.C. Amico, Carbon fiber-reinforced epoxy filament-wound composite laminates exposed to hygrothermal conditioning. J. Mater. Sci., 51 (9) (2016), pp. 4697-4708

[23] B. Hong, G. Xian, Z. Wang, Durability study of pultruded carbon fiber reinforced polymer plates subjected to water immersion. Adv. Struct. Eng., 21 (4) (2017), pp. 571-579

[24] B. Hong, G. Xian, Ageing of a thermosetting polyurethane and its pultruded carbon fiber plates subjected to seawater immersion. Constr. Build. Mater., 165 (2018), pp. 514-522

[25] B. Hong, G. Xian, H. Li, Effects of water or alkali solution immersion on the water uptake and physicochemical properties of a pultruded carbon fiber reinforced polyurethane plate. Polym. Compos. (2018)

[26] A.Y. Zhang, D.H. Li, D.X. Zhang, Effect of moisture absorption on the bending strength of CFRP. Adv. Mater. Res., 450-451 (2012), pp. 482-485

[27] S. Takeda, T. Tsukada, S. Sugimoto, Y. Iwahori, Monitoring of water absorption in CFRP laminates using embedded fiber Bragg grating sensors. Composites Part A, 61 (2014), pp. 163-171

[28] H. Saadatmanesh, M. Tavakkolizadeh, D. Mostofinejad, Environmental effects on mechanical properties of wet lay-up fiber-reinforced polymer. ACI Mater. J., 107 (3) (2010), pp. 267-275

[29] M.S. Sciolti, M. Frigione, M.A. Aiello, Wet lay-up manufactured FRPs for concrete and masonry repair: influence of water on the properties of composites and on their epoxy components. J. Compos. Constr., 14 (6) (2010), pp. 823-833

[30] B. Benmokrane, A. Manalo, J. Bouhet, K. Mohamed, M. Robert, Effects of diameter on the durability of glass fiber-reinforced polymer bars conditioned in alkaline solution. J. Compos. Constr., 21 (5) (2017), p. 40170405

[31] M. Wang, Z. Zhang, Y. Li, M. Li, Z. Sun, Chemical durability and mechanical properties of alkali-proof basalt fiber and its reinforced epoxy composites. J. Reinf. Plast. Comp., 27 (4) (2008), pp. 393-407

[32] X. Jiang, H. Kolstein, F. Bijlaard, X. Qiang, Effects of hygrothermal aging on glass-fibre reinforced polymer laminates and adhesive of FRP composite bridge: Moisture diffusion characteristics. Composites Part A, 57 (2014), pp. 49-58

[33] K. Majerski, B. Surowska, J. Bienias, The comparison of effects of hygrothermal conditioning on mechanical properties of fibre metal laminates and fibre reinforced polymers. Composites Part B (2018)

[34] V.M. Karbhari, J.W. Chin, D. Hunston, B. Benmokrane, T. Juska, R.Morgan, et al., Durability gap analysis for Fiber-Reinforced Polymer Composites in civil infrastructure. J. Compos. Constr., 7 (3) (2003), pp. 238247

[35] Y. Miyano, M. Nakada, N. Sekine, Accelerated testing for long-term durability of FRP laminates for marine use. J. Compos. Mater., 39 (1) (2005), pp. 5-20

[36] Y. Chen, J.F. Davalos, I. Ray, Durability prediction for GFRP reinforcing bars using short-term data of accelerated aging tests. J. Compos. Constr., 10 (4) (2006), pp. 279-286

[37] Y. Chen, J.F. Davalos, I. Ray, H. Kim, Accelerated aging tests for evaluations of durability performance of FRP reinforcing bars for concrete structures. Compos. Struct., 78 (1) (2007), pp. 101-111 
[38] M. Robert, P. Wang, P. Cousin, B. Benmokrane, Temperature as an accelerating factor for long-term durability testing of FRPs: Should there be any limitations? J. Compos. Constr., 14 (4) (2010), pp. 361367

[39] A.C.I. Committee, Guide test methods for fiber-reinforced polymers(FRPs) for reinforcing or strengthening concrete structures. Am. Concr. Inst. (2004)

[40] American Society for Testing and Materials. Standard test method for tensile properties of plastics, 2000.

[41] American Society for Testing and Materials. Standard test methods for flexural properties of unreinforced and reinforced plastics and electrical insulating materials, 2003.

[42] V.M. Karbhari, Durability of Composites for Civil Structural Applications. Woodhead Publishing, Witney, Oxford, UK (2007)

[43] H. Hojo, K. Tsuda, K. Ogasawara, Form and rate of corrosion of corrosion-resistant FRP resins. Adv. Compos. Mater., 1 (1) (1991), pp. 55-67

[44] K. Tsuda, Behavior and mechanisms of degradation of thermosetting plastics in liquid environments. J. Jpn. Petrol. Inst., 50 (5) (2007), pp. 240-248

[45] Y.L. Wang, X. Zhang, G.C. Cai, B.L. Wan, D. Waldmann, Y. Qu, A new thickness-based accelerated aging test methodology for resin materials: theory and preliminary experimental study. Constr. Build. Mater., 186 (2018), pp. 986-995

[46] Y.L. Wang, Y.S. Wang, B.L. Wan, B.G. Han, G.C. Cai, Z.Z. Li, Properties and mechanisms of self-sensing carbon nanofibers/epoxy composites for structural health monitoring. Compos. Struct., 200 (2018), pp. 669-678 